\title{
Breast Cancer Treatment Consensus St. Gallen 2007: Unity in Diversity?
}

\author{
Hans-Jörg Senn \\ Tumor- und Brustzentrum ZeTuP St. Gallen und Chur, Switzerland
}

From March 14-17 2007, the 10th international conference on 'Primary Therapy of Early Breast Cancer' took place in the OLMA-Kongress-Zentrum in St. Gallen - a small anniversary! More than 4,700 delegates from 95 countries of every continent participated, 500 more than 2 years ago. The question is, were their high expectations met by this worldrenowned event which in its 10th edition traditionally ended on Saturday morning with the 'spectacle' of an open consensus meeting on the currently optimal spectrum of therapy options for operable early breast cancer?

In equally traditional manner, the convention was opened with an up-to-date 'Tour d'Horizont' presenting the latest news in breast cancer biology, diagnosis, and therapy since the 2005 St. Gallen Breast Cancer Conference. This cutting-edge opening session unambiguously explained the often questioned reason behind the 2-year conference interval which has occurred since 2001: Both, the rate of accrual of tumor biological data and the ever-changing therapy recommendations emerging from large clinical trials necessitated a reduction of the interval from the original 4 to 3 and now 2 years. In addition, the current interval also accommodates an agreement made in 2001 with the organizers of the 'European Breast Cancer Conference' not to conduct the two Europe-wide most important breast cancer events in the same years but - following prospective arrangement - alternately every second March, which has proved successful for many years.

The 2007 international St. Gallen Consensus Panel comprises as many as 39 panelists and is headed by the two chairmen, Professor Aron Goldhirsch (Lugano, Switzerland/Milano, Italy) and Professor John William Wood (Atlanta, USA). For this year's convention, the panel had to work harder and prepare in more detail than ever before. Data of recent clinical studies and publications received prior to the conference had to be critically evaluated in order to include appropriate findings in the 2007 consensus. Right at the beginning of the con- sensus session, the accuracy of the courageous 2005 policy change regarding the choice of treatment in the adjuvant setting was confirmed. This change entailed bringing to the fore the biology of the tumor - in particular its endocrine responsiveness (hormone receptors, Her2 status etc.) - replacing the mainly pathological-anatomically defined tumor relapse risk as the main criterion for the therapy decision. In particular some US experts had initially strongly opposed this change of strategy, which incidentally was one of the reasons why the former publishing medium for the recommendations of the St. Gallen Breast Cancer Consensus, the (American) Journal of Clinical Oncology, was replaced by the (European) Annals of Oncology.

In the course of the intended 'globalization' of the St. Gallen consensus process, it has unfortunately become apparent, for various reasons, that the attempted extension of the consensus panel in terms of personnel, expertise and geographic origin has resulted in some negative side effects: The consensus process is becoming more and more difficult, particularly where there is a lack of definite and all-round convincing level-1 study data, and where the national or area-of-expertise-related differences in the rating of the relevance of those study data neutralize one another. On the other hand, it is inevitable that with certain questions no consensus can yet be reached due to currently unclear data (e.g., indications for use of taxanes, duration of therapy with LHRH agonists or even trastuzum-

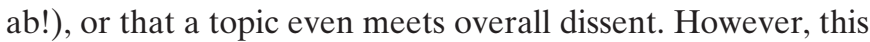
mainly affects those practitioners who are unfamiliar with breast cancer therapy and wrongly use such consensus recommendations as 'recipes' instead of referring their patients to experienced specialists in recognized breast centers.

The 2007 St. Gallen Consensus Meeting has again shown particularly that the unsolved and controversial problems and question marks of breast cancer therapy on which no consensus can yet be reached are potential focal points and incen-

\begin{tabular}{ll}
\hline KARGER & @ 2007 S. Karger GmbH, Freiburg \\
Fax +4976145207 14 & Accessible online at: \\
$\begin{array}{l}\text { E-mail Information@Karger.de } \\
\text { www.karger.com }\end{array}$ & www.karger.com/brc
\end{tabular}

Prof. Dr. med. Hans-Jörg Senn

Tumor- und Brustzentrum ZeTuP St. Gallen und Chur

Rorschacherstrasse 150

9006 St. Gallen, Switzerland

Fax +41 71 243-0044

E-mail hjsenn@sg.zetup.ch 
tives for new relevant experimental and clinical studies. In that sense, the 'therapeutic dialogue' behind the scenes between experts of different fields and countries of origin is often more important than the obviously visible and audible results of such an event!

The 2007 St. Gallen Breast Cancer Therapy Consensus has already been accepted by the editorial office of Annals of Oncology and can be viewed online in this renowned journal in the next few weeks (http://annonc.oxfordjournals.org). In the meantime, strange as it may seem, preparations have already started for the 11th International St. Gallen Conference on the subject of 'Primary Therapy of Early Breast Cancer', which will take place March 11-14, 2009. And given the large number of current clinical studies, the next consensus panel will have plenty of food for discussion and decision provided by problems and unsolved questions regarding optimal breast cancer therapy. 